\title{
Endothelial hypoxic metabolism in carcinogenesis and dissemination : HIF-A isoforms are a NO metastatic phenomenon
}

\author{
Cristina Branco-Price ${ }^{1}$, Colin E. Evans ${ }^{1}$, and Randall S. Johnson ${ }^{1}$ \\ ${ }^{1}$ Department of Physiology, Development and Neuroscience, University of Cambridge, Cambridge, UK \\ Correspondence to: Randall S. Johnson, email: rsj33@cam.ac.uk \\ Keywords: Vascular endothelium, hypoxia, metastasis, HIF, HIF isoforms, nitric oxide, cell-specific responses \\ Received: October 2, $2013 \quad$ Accepted: November 16, $2013 \quad$ Published: November 18, 2013
}

This is an open-access article distributed under the terms of the Creative Commons Attribution License, which permits unrestricted use, distribution, and reproduction in any medium, provided the original author and source are credited.

\section{ABSTRACT:}

Tumor biology is a broad and encompassing field of research, particularly given recent demonstrations of the multicellular nature of solid tumors, which have led to studies of molecular and metabolic intercellular interactions that regulate cancer progression. Hypoxia is a broad stimulus that results in activation of hypoxia inducible factors (HIFs). Downstream HIF targets include angiogenic factors (e.g. vascular endothelial growth factor, VEGF) and highly reactive molecules (e.g. nitric oxide, NO) that act as cell-specific switches with unique spatial and temporal effects on cancer progression. The effect of cell-specific responses to hypoxia on tumor progression and spread, as well as potential therapeutic strategies to target metastatic disease, are currently under active investigation. Vascular endothelial remodelling events at tumor and metastatic sites are responsive to hypoxia, HIF activation, and NO signalling. Here, we describe the interactions between endothelial HIF and NO during tumor growth and spread, and outline the effects of endothelial HIF/NO signalling on cancer progression. In doing so, we attempt to identify areas of metastasis research that require attention, in order to ultimately facilitate the development of novel treatments that reduce or prevent tumor dissemination.

\section{INTRODUCTION}

In the last decade, tumors have been redefined as multicellular organs, a notion that replaced the previously confined view that tumors are pluricellular masses [1], and which restricted both the understanding of the biology of cancer, and the development of effective therapeutic strategies. Specific and substantial roles of nonmalignant cells in cancer progression (tumor growth and metastasis) have recently been elucidated, and therapeutic focus has begun to shift away from the tumor cells themselves towards a broader spectrum of cellular and molecular targets [2, 3], all inter-dependent components of a plastic, adaptive and mobile organ with powerful survival strategies. Despite vast research on the tumor microenvironment, however, alternative cancer treatments aimed at non-malignant cells remain elusive [4-6].

The processes of tumor growth and dispersion are highly complex, given that each cell type responds to different stimuli in a unique fashion. Multiple biochemical, mechanical, and signalling pathways define disease advancement, and in doing so, modulate clinical outcome [5-7]. Assessing the progression of cancer is currently forced to incorporate this organic complexity whereby the contribution of different cell types to the processes of tumor growth, aggressiveness, dispersion and response to therapy is accounted for. Therefore, physiological and metabolic adaptations of cells within the tumor and metastatic environment have to be assessed individually and taking into consideration the synergistic impact on the others $[7,8]$.

Tumor growth and spread is strongly affected by, for example, the endothelial cell (EC) response to hypoxia [9]. We and others recently demonstrated that this response controls metastatic success, to a significant extent, via hypoxia-inducible factors (HIFs) $[10,11]$ and nitric oxide (NO) [11]. Our study unveiled a role for endothelial HIF/NO-dependent signalling in metastasis, which is differentially regulated by the two major HIF isoforms (HIF1-alpha and HIF2-alpha) that severely impact upon the ability of tumor cells to successfully establish distant metastases [11]. In this study, HIF1-alpha was shown to 
have a pro-metastatic effect, while HIF2-alpha opposed metastasis, and although we speculated that these effects occur via NO- and vascular endothelial growth factor (VEGF)-mediated changes in vessel permeability (Figure 1), the mechanisms by which endothelial HIF/ NO signalling intervenes in metastasis are not fully understood. The aim of this perspective is to summarise the diverse functions of endothelial and HIF/NO signalling during cancer progression, and to discuss the potential impact of these findings on future studies leading towards the development of novel adjunctive cancer therapies.

\section{HIF-mediated response to hypoxia during cancer progression}

Hypoxia is a trademark of solid tumors that is associated with poor prognosis and successful metastases [12-14]. The HIF-mediated control of this response has been comprehensively characterized [15-18], and the role of these transcription factors is presently acknowledged to be cell-specific [19]; mechanisms and factors regulating HIF-a stability as well as the target genes and pathways regulated by them vary between different cell types and in different conditions, which include stimuli other than hypoxia $[12,19]$.

For that reason, the attractive strategy of targeting HIF1-alpha for cancer therapy needs to be observed and integrated in a multicellular and temporal context; Although HIF1-alpha (and in some cases HIF2-alpha) activity in tumor cells, for example, is a clear indicator of poor prognosis $[12,17,20]$, in other cell types this may not be the case [11]; many other non-malignant cell types within the tumor microenvironment have been shown to significantly contribute to the regulation of cancer progression [3], especially macrophages [21, 22] and fibroblasts [23] which, among other things, greatly contribute to the paracrine VEGF signalling that leads to aberrant vascularization. ECs, specifically, both at the tumor stroma [24] and at the extravasation sites [11] also have unique responses to hypoxia $[25,26]$ and play a critical role tumor dispersion [24].

\section{Endothelial cell-specific response to hypoxia}

ECs are mostly glycolytic and their hypoxic response is triggered at lower oxygen concentrations compared with other cell types [25]. Although the machinery and capacity to respond to less severe hypoxia is present and functional in ECs, this discrepancy appears to involve intricate mechanisms, and the activation of HIF in these cells is sensitive to minor oscillations in oxygen tension as well as other chemical signals [26-28].

Reductions in oxygenation that occur in a solid tumor directly impact upon the endothelium, which can act as a barrier or vehicle for metastasising cells. Hypoxic conditions, as mentioned above, are associated with a leaky and inefficient vasculature that compromises the barrier function of the blood vessels against infiltrating cells. At the site of extravasation, hypoxia could occur locally, for example, when migrating cells arrest in the capillary bed prior to seeding at secondary sites [29, 30].

In the case of the characteristic tortuous and inefficient tumor vasculature, the blood flow and consequently oxygen delivery is insufficient. ECs sense and respond to this stimulus by activating mechanisms that lead to increased proliferation; this is supported by an increase in endogenous and exogenous VEGF levels and associated receptors, migration (required for vascular branching and angiogenesis) and activation of hypoxic metabolism that ensures survival and amelioration of the hypoxic condition [31]. Specifically, tumor ECs: (i) enable the delivery of oxygen and nutrients to the tumor; (ii) form a physical barrier between the tumor mass and the remaining organism; (iii) act as a vehicle through which detached tumor cells travel to distant organs; and (iv) provide an anchor required for survival of micrometastases $[32,33]$. By directly interacting with other cell types in the tumor microenvironment (e.g. inflammatory cells, tumor cells, platelets), ECs can aid or impair tumor growth and spread [7, 34, 35].

Mechanisms that regulate the generation and function of the tumor vasculature have therefore been the target of many experimental and clinical studies that aim to reduce tumor propagation [36]. Although tumor size is often initially reduced by anti-angiogenic treatments (e.g. HIF and VEGF inhibitors), such therapies frequently have short-lived effectiveness, and long term benefits are not only seldom observed, but can also result in higher metastatic incidence [4, 37]. These findings have highlighted the complex and multi-factorial nature of the HIF-mediated angiogenic response to hypoxia during cancer progression $[27,38]$, one component of which is regulated solely by EC-specific HIF.

\section{HIF-mediated response in hypoxic EC during cancer progression}

Effects of EC-specific HIF signalling on cancer progression have been elucidated in the last decade, often using Cre-LoxP-mediated deletion of EC HIFalpha driven by the Tie 2 or VE-cadherin promoters in mice $[11,12]$. Mice with EC-specific deletion of HIF1alpha, for example, develop smaller subcutaneous tumors compared with those implanted into wild-type littermates [27]; EC-specific deletion of HIF2-alpha compromises neovascularization and vessel remodelling [38]. ECspecific HIF1-alpha knockout also reduces metastases in the Polyoma middle T (PyMT) mouse model of mammary cancer, and attenuates extravasation in mice subjected to intravenous tumor cell injections [11]. 
Studies using mouse models of cancer with ECspecific deletion of HIF2-alpha have also shown reduced tumor growth rates compared with wild type mice [10], but the effect of EC-specific HIF2-alpha deletion on metastatic efficiency in these mice has been reported as being advantageous [10] and deleterious [11]. The role of the endothelium in mediating metastatic disease, the location and timing of HIF-signalling and the contribution of NO to cancer progession is a puzzle with possibly multiple solutions. It is therefore worthwhile identifying the pathways activated downstream of these main regulators as potential targets for therapy, in alternative or in addition to targeting them directly.

The role of EC-specific HIF signalling in metastatic disease is an active area of research in our laboratory. In multiple cell types, one important downstream effector of the HIF-mediated responses is the metabolic regulator, NO [39-41]. In addition to all the functions performed by this highly reactive molecule, there is currently a plethora of information that directly correlates NO with cancer progression, metastases and clinical outcome [42, 43].

\section{Response to hypoxia during cancer progression: contribution of Nitric Oxide}

$\mathrm{NO}$ is an ephemeral but highly reactive molecule with direct cytotoxic effects [44]. NO can be generated as a result of hypoxia, given that the inducible form of nitric oxide synthase (iNOS) is a target of HIF1-alpha [45, 46]. Conversely, NO can also be a cause for metabolic hypoxia, given that competition with oxygen at cytochrome $c$ results in diversion of oxygen to other pathways [46, 47]. NO has also been shown to increase HIF1-alpha degradation

\section{A. Primary tumor}

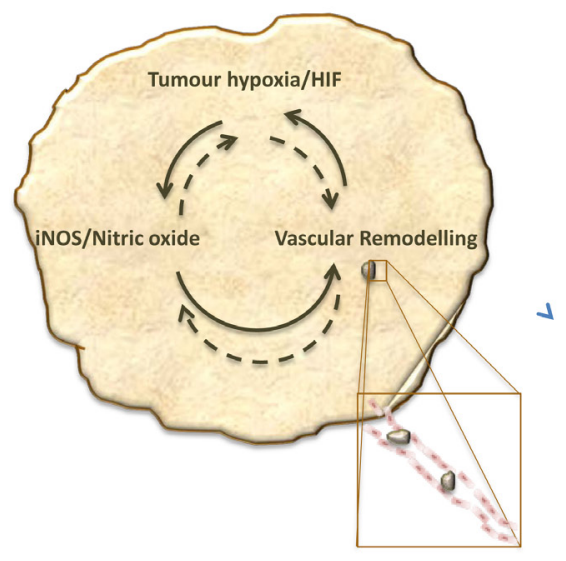

INTRAVASATION during hypoxia [48], and is negatively correlated with blood oxygen saturation, for example during arthritis development [49].

\section{NO signalling in cancer progression and metastases.}

During carcinogenesis, NO is generated by different cell types, in different amounts, and via different regulatory mechanisms [39]. In human breast tumors, for example, higher levels of NO are found in malignant tissues compared with benign masses, and these levels increase as tumors progress, independent of other prognostic parameters such as estrogen receptor level, human epidermal growth factor receptor (HER) or menopausal status [50].

Although the role of NO is well established in other pathological settings, such as the regulation of vascular tone, the inflammatory response, and mitochondrial respiration $[48,51-53]$ its impact on tumor progression and metastatic processes appears ambiguous [44, 54]. Studies have previously suggested both facilitating and hampering effects of $\mathrm{NO}$ on tumor growth and metastatic success.

$\mathrm{NO}$ is known to function as a pro-apoptotic agent [54-56] and as such can promote tumor cell death [39]. This property has lead to the suggestion that NO donors could be used to limit tumor growth, and it has also been argued that NO donors could improve efficacy of chemo and radiotherapy by counteracting desensitization and resistance [57-59].

On the other hand, findings that argue for a protumorigenic role of NO are varied. For example, excessive

\section{B. Metastatic site}

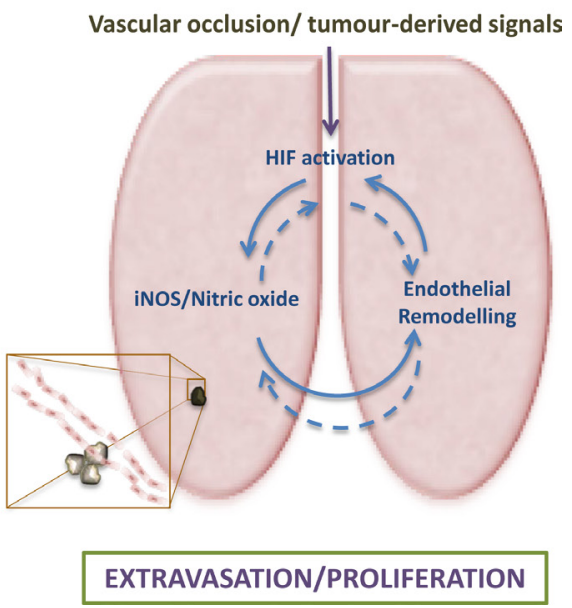

Figure 1: Endothelial HIF/NO-mediated regulation of metastases at primary tumor and metastatic sites. (A) Hypoxia and subsequent HIF-a stabilization are common trademarks of solid tumors, which affect the myriad of cellular components within the tumor, and lead to cell type-specific responses, including NO-mediated endothelial remodelling that increases vascular leakiness and drives intravasation. (B) Endothelial HIF and NO signalling also affect extravasation and possibly post-extravasation proliferation of tumor cells; remodelling responses to HIF activation and NO induction in the endothelium, however, can be tissue- and isotype-specific. 
Table 1: Studies investigating the role of endothelial HIF/NO/VEGF signalling in cancer progression

\begin{tabular}{|c|c|c|c|}
\hline Methods & Results & Conclusions & Ref \\
\hline $\begin{array}{l}\text { EC HIF1-alpha and 2-alpha } \\
\text { knockout mice with: } \\
\text { (a) Implanted subcutaneous and } \\
\text { spontaneous mammary tumors } \\
\text { (b) Intravenous Lewis lung cancer } \\
\text { cells } \\
\text { Migration of cancer cells across ECs }\end{array}$ & $\begin{array}{l}\text { EC HIF1-alpha knockout reduced: } \\
\text { (a) NO synthesis } \\
\text { (b) Cancer cell migration across } \\
\text { ECs } \\
\text { (c) Metastatic success } \\
\text { EC HIF2-alpha knockout had the } \\
\text { opposite effect }\end{array}$ & $\begin{array}{l}\text { EC HIF1-alpha and HIF2- } \\
\text { alpha have opposing roles in the } \\
\text { regulation of metastatic seeding } \\
\text { HIF-alpha acts in a cell- and } \\
\text { isoform-specific manner }\end{array}$ & {$[11]$} \\
\hline Analysis of human mammary tumor & \begin{tabular}{|l} 
eNOS, HIF1-alpha, iNOS, and \\
VEGF, were present \\
There were correlations between: \\
(a) eNOS and HIF1-alpha, VEGF, \\
or VEGFR2 \\
(b) VEGF and VEGFR2
\end{tabular} & $\begin{array}{l}\text { HIF1-alpha/NO/VEGF signalling } \\
\text { appears to be active in human } \\
\text { breast cancer }\end{array}$ & {$[87]$} \\
\hline $\begin{array}{l}\text { EC HIF2-alpha knockout mice with } \\
\text { autochthonous skin tumors } \\
\text { Migration, proliferation, adhesion, } \\
\text { and invasion of HIF2-alpha } \\
\text { knockout ECs }\end{array}$ & $\begin{array}{l}\text { EC HIF2-alpha knockout impaired: } \\
\text { (a) Functional tumor angiogenesis } \\
\text { (b) Tumor perfusion } \\
\text { (c) Adhesion to collagen } \\
\text { EC HIF2alpha knockout increased: } \\
\text { (a) Migration and invasion } \\
\text { (b) Tube formation }\end{array}$ & $\begin{array}{l}\text { EC HIF2-alpha is required for } \\
\text { tumor vessel growth } \\
\text { Roles of EC HIF1alpha and 2alpha } \\
\text { in pathological angiogenesis are } \\
\text { distinct }\end{array}$ & {$[38]$} \\
\hline $\begin{array}{l}\text { Analysis of human esophageal } \\
\text { tumor }\end{array}$ & $\begin{array}{l}\text { HIF1-alpha was present in tumors } \\
\text { There were associations between: } \\
\text { (a) HIF1-alpha, VEGF, and iNOS } \\
\text { (b) eNOS and VEGF }\end{array}$ & $\begin{array}{l}\text { HIF1-alpha, iNOS, and VEGF } \\
\text { expression is linked in human } \\
\text { esophageal cancer }\end{array}$ & {$[88]$} \\
\hline $\begin{array}{l}\text { EC HIF2-alpha knockout mice with } \\
\text { xenograft tumors } \\
\text { Vascularisation, apoptosis, and } \\
\text { adhesion of HIF2alpha knockout } \\
\text { ECs }\end{array}$ & $\begin{array}{l}\text { EC HIF2-alpha knockout impaired: } \\
\text { (a) Vessel integrity } \\
\text { (b) EC structure } \\
\text { (c) Tumor angiogenesis } \\
\text { (d) EC adhesion }\end{array}$ & $\begin{array}{l}\text { EC HIF2-alpha is required for } \\
\text { normal EC function and vessel } \\
\text { formation } \\
\text { EC HIF1-alpha and 2-alpha have } \\
\text { distinct roles in angiogenesis }\end{array}$ & {$[10]$} \\
\hline $\begin{array}{l}\text { EC HIF1-alpha knockout mice with } \\
\text { implanted subcutaneous tumors } \\
\text { Proliferation, migration, invasion, } \\
\text { and tube formation of HIF1-alpha } \\
\text { knockout ECs }\end{array}$ & $\begin{array}{l}\text { EC HIF1alpha knockout inhibited: } \\
\text { (a) Proliferation, migration, and } \\
\text { invasion } \\
\text { (b) Tumor angiogenesis and } \\
\text { growth }\end{array}$ & $\begin{array}{l}\text { EC HIF1/VEGF signalling is } \\
\text { crucial for cell function during } \\
\text { tumor angiogenesis }\end{array}$ & {$[27]$} \\
\hline
\end{tabular}

levels of $\mathrm{NO}$ and subsequent oxidative stress, lead to DNA and protein damage, thereby increasing mutation rates and consequently enhancing tumor aggressiveness $[44,55]$; Furthermore, iNOS expression in many human and murine cancers correlates with poor prognosis and decreased disease-free survival [41, 60]. NO is also known as a mediator of angiogenesis [41], therefore contributing to tumor growth and dissemination. NO-driven metabolic hypoxia was also shown to affect angiogenesis, hyperplasia, and the formation of inflammatory lesions breast cancer patients [50] while iNOS depletion or inhibition in murine breast cancer models consistently results in reduced tumor growth and metastases $[11,61$, 62]. The presence of NO has also been shown to decrease immune cell-mediated tumor cell death via inhibition of HIF1 under hypoxia [59], and chemokine nitration within the tumor microenvironment appears to be one of the mechanisms by which tumor NO prevents T-cell infiltration $[40,63]$.

Although NO is clearly produced in tumor cells [40, 41, 60, 61, 64], alternative cellular sources of NO are seldom reported, as are their spatial and temporal expression patterns of the NOS isoforms. Moreover, metabolic effects of $\mathrm{NO}$ on cancer progression at the primary tumor site and particularly at the site of metastasis require further investigation.

\section{HIF and/or NO: coordinated regulation of EC metabolism during tumor growth and metastasis}

A number of studies have investigated the potential effects of endothelial HIF-mediated NO signalling 
on cancer progression (Table I). It has been shown, for example, that cyclic hypoxia (likely induced by heterogeneous and deregulated blood flow in solid tumors) increases EC survival through HIF1-alpha stabilization, and that eNOS attenuates HIF1-alpha expression and interferes with cell respiration [26, 65]. Furthermore, EC survival in response to cyclic hypoxia is increased by NOS inhibition [65].

NO mimetic agents have also been shown to suppress HIF1-alpha accumulation under hypoxia [66]; interestingly, several studies report that the accumulation of angiogenic VEGF is directly correlated with $\mathrm{NO}$ levels $[67,68]$. We showed that EC-specific VEGF levels decrease in the absence of iNOS expression or activity and increase in the presence of an NO donor, and that this occurs in direct correlation with metastatic success [11]. iNOS-dependent VEGF production has also been reported elsewhere [64, 69, 70].

The EC response to hypoxia affects processes that contribute to tumor progression and spread, including vessel permeability, tumor cell migration, proliferation, and interaction with other cells relevant for tumor cell seeding and establishment, including inflammatory cells and platelets [71-73] NO stimulates proliferation, migration, and differentiation of ECs to form new blood vessels [28], but again positive [74] and negative [75] effects of $\mathrm{NO}$ on vascular permeability have been reported.

Contrasting effects of endothelial HIF/NO signalling on cancer progression could again be a result of differences in cell/tissue type, NOS isoform, and NO levels between studies. Most studies on endothelial-derived NO production have been circumscribed to the levels and activity of eNOS, which is constitutively expressed and widely accepted as the major determinant of $\mathrm{NO}$ production in ECs. It has also been reported, however, that the major function of eNOS is to maintain residual levels of NO, which in turn ensures that endothelial permeability and vascular tension are stable [45]. Conversely, sharp and dramatic increases in NO levels are usually a result of iNOS activit; iNOS is more abundant and readily induced in murine compared with human ECs, which are more reliant on concomitant cytokine stimulation in addition to HIF1-alpha activation [45]. Endothelial cells from different tissues and organs, whether in physiological or cultured conditions also display different gene expression and stress responses [76, 77]; this is yet another level of intricacy of the mechanisms underlying cell-cell interactions that control or predispose certain vascular beds to metastatic events.

Given that EC behaviour varies between organs $[77,78]$, the effect of EC HIF/NO signalling on tumor growth and metastasis may also depend on cancer type and metastatic site. NO production in mouse models of breast cancer is directly correlated with VEGF levels, but the pathway(s) that link cell-specific HIF/NO signalling with cancer outcomes such as tumor growth and metastasis

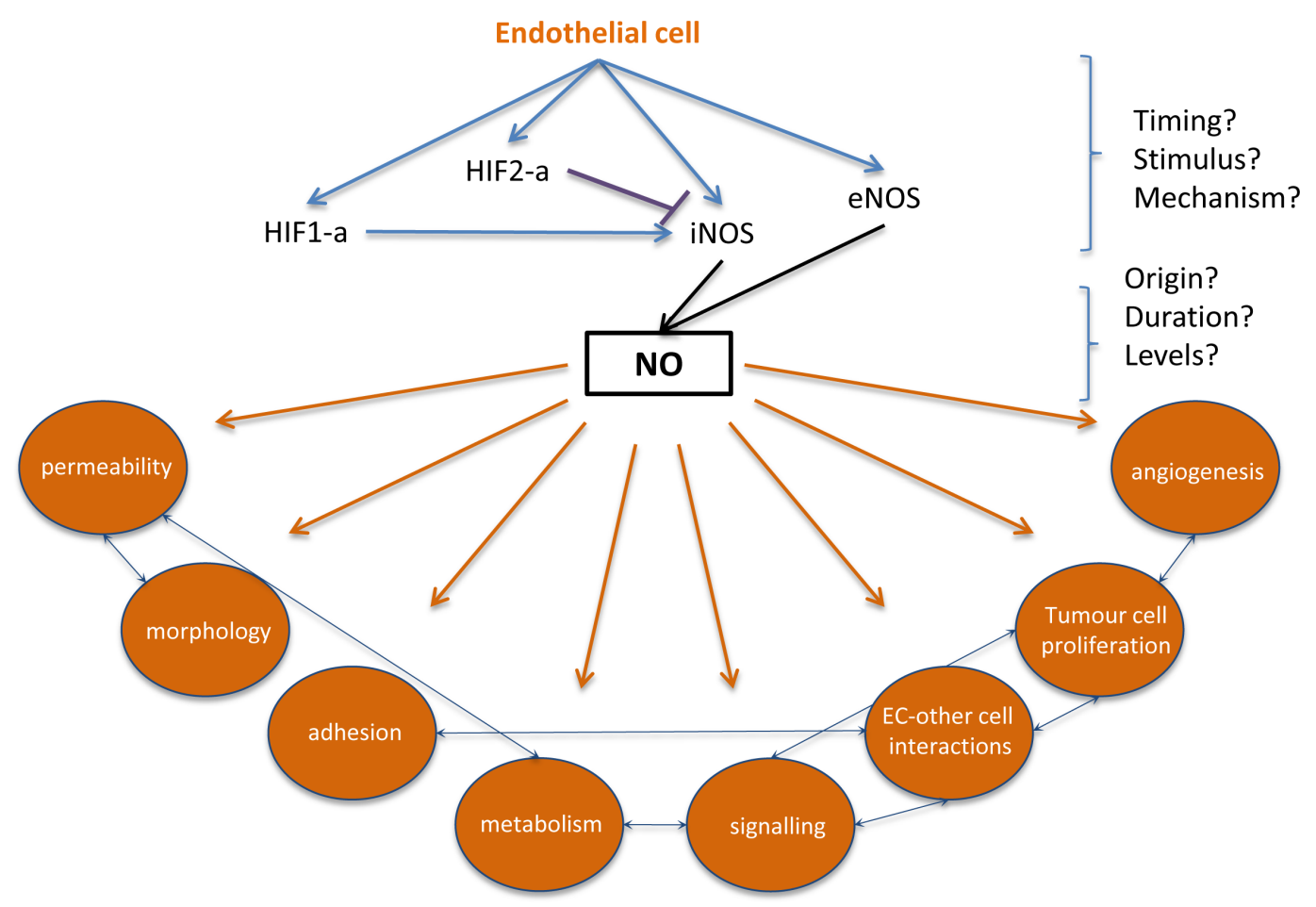

Figure 2: Filling the gaps in endothelial HIF-alpha, NO signalling and subsequent changes that can contribute to metastatic events. At the site of extravasation, endothelial HIF-1a or HIF-2a activation results in differential activation of iNOS, with direct influences on NO production. Hypoxia- and HIF-independent signals can also stimulate NO production, and the origin, concentration, and duration of NO may affect metastatic success. Downstream effects of endothelial HIF/NO signaling, such as endothelial permeability and endothelial cell-tumor cell adhesion, could be targeted to reduce or prevent extravasation. 
remain incompletely understood. One current aim in our laboratory is therefore to fully characterise the HIF/ NO-mediated response to hypoxia in ECs, and to study downstream effects of EC HIF/NO signalling on cancer progression, using mouse models of cancer and cellspecific deletion of HIF-alpha or iNOS.

\section{PERSPECTIVES: CURRENT AND FUTURE WORK}

Key questions remain when characterizing the role of the vasculature in metastatic disease, e.g. what roles do EC-specific HIF and NO play during intravasation, and what cell-specific molecular signalling pathways regulate the extravasation and viability of colonizing cancer cells? Although mechanisms that regulate endothelial HIF/NOmediated cancer progression are not fully understood, therapeutic or gene-mediated disruption of this signalling cascade could potentially reduce metastatic success (Figure 2).

In the primary tumor microenvironment, it is known that hypoxia triggers HIF1-alpha stabilization in different cell types. Subsequently, target genes including VEGF are transcriptionally up-regulated and cooperate to facilitate tumor growth and intravasation [79]. Factors that regulate stabilization of the HIF isoforms and iNOS in ECs at the site of extravasation however, are largely unknown and may be hypoxia-independent $[80,81]$.

Transient hypoxic events are likely to occur when circulating tumor cells obstruct small capillaries, for example in the lungs. The molecular outcome of those events would depend on a myriad of factors including duration and severity of hypoxic stimulus, as well as cell type(s) affected, and this could ultimately determine the extent to which each HIF-alpha isoform is stabilised, and in turn affect local NO levels that control extravasation. HIF/NO signalling in ECs, for example, could regulate metastasis by affecting vessel permeability (via disruption of endothelial junctions) or interaction between the endothelium and tumor cells (via cell adhesion molecules). HIF and/or iNOS could also be stabilized at the site of extravasation prior to the arrival of colonizing tumor cells, as a result of tumor-derived signals that circulate systemically $[82,83]$ For example, hypoxia-independent chemical stimuli could arise from the primary tumor $[15$, $73,83]$.

Given that cancer cell extravasation and metastatic colonization are rate-limiting steps that involve reciprocal interactions between tumor cells and host stroma [84-86], it will be crucial to understand the molecular and cellular mechanisms that regulate these interactions. To investigate whether endothelial HIF-alpha and/or iNOS have any role in assisting or preventing the establishment of tumor cells at secondary metastatic sites, lung endothelium can be exposed to hypoxia in EC-specific HIF-alpha null, NO null, or wild type mice (Branco-Price, unpublished data), and metastatic foci subsequently quantified using a mouse model of extravasation [11]. In order to characterise the spatial and temporal patterns of HIF-alpha isoforms and NO expression during cancer progression, we are also currently quantifying their levels at various metastatic sites and stages of tumor development.

Simple immunohistochemical and biochemical approaches can be used to investigate changes in cellspecific HIF-alpha isoform stabilization and their associated changes in vascular integrity that modulate metastasis. These techniques can also be used to localise hypoxic foci and predict the stage of tumor development at which HIF-directed therapy would be beneficial or detrimental. Discovering whether HIF activation is a result of local hypoxic loci and/or systemic signals from the primary tumor would improve our understanding of metastasis significantly, and elucidation of HIF/NOmediated mechanisms that regulate tumor dispersion could lead to the development of novel therapies to counteract this process.

One of the questions that have to be addressed is which HIF-alpha isoforms in the lung endothelium of tumor bearing mice are active, alternatively or simultaneously, and what is regulating that equilibrium.

\section{CONCLUSIONS}

The EC HIF/NO signaling pathway plays a crucial role in cancer progression. Such cellular and molecular pathways may be targeted in order to reduce tumor growth and spread. Given that: (i) hypoxic stress can cause differing levels of induction of the two HIF-alpha isoforms; (ii) HIF/NO-mediated responses to hypoxia during cancer progression are cell type-specific; and (iii) current HIF-alpha inhibitors are not cell type- or HIF isoform-specific, novel therapies should attempt to target individual HIF isoforms in defined cell sub-populations within the tumor microenvironment. Alternative or additional therapeutic approaches could also arise through targeting of factors downstream of EC HIF/NO.

\section{REFERENCES}

1. Hanahan D and Weinberg RA. Hallmarks of cancer: the next generation. Cell. 2011; 144(5):646-674.

2. Swartz MA, Iida N, Roberts EW, Sangaletti S, Wong MH, Yull FE, Coussens LM and DeClerck YA. Tumor microenvironment complexity: emerging roles in cancer therapy. Cancer Res. 2012; 72(10):2473-2480.

3. Hanahan D and Coussens LM. Accessories to the crime: functions of cells recruited to the tumor microenvironment. Cancer Cell. 2012; 21(3):309-322.

4. Fokas E, McKenna WG and Muschel RJ. The impact of tumor microenvironment on cancer treatment and its modulation by direct and indirect antivascular strategies. 
Cancer Metastasis Rev. 2012; 31(3-4):823-842.

5. Horimoto Y, Polanska UM, Takahashi Y and Orimo A. Emerging roles of the tumor-associated stroma in promoting tumor metastasis. Cell Adh Migr. 2012; 6(3):193-202.

6. Langley RR and Fidler IJ. The seed and soil hypothesis revisited--the role of tumor-stroma interactions in metastasis to different organs. Int J Cancer. 2011; 128(11):2527-2535.

7. Witz IP. Tumor-microenvironment interactions: dangerous liaisons. Adv Cancer Res. 2008; 100:203-229.

8. Mierke CT. Endothelial cell's biomechanical properties are regulated by invasive cancer cells. Mol Biosyst. 2012; 8(6):1639-1649.

9. Evans CE, Branco-Price C and Johnson RS. HIF-mediated endothelial response during cancer progression. Int $\mathrm{J}$ Hematol. 2012; 95(5):471-477.

10. Skuli N, Liu L, Runge A, Wang T, Yuan L, Patel S, IruelaArispe L, Simon MC and Keith B. Endothelial deletion of hypoxia-inducible factor-2alpha (HIF-2alpha) alters vascular function and tumor angiogenesis. Blood. 2009; 114(2):469-477.

11. Branco-Price C, Zhang N, Schnelle M, Evans C, Katschinski DM, Liao D, Ellies L and Johnson RS. Endothelial cell HIF-1alpha and HIF-2alpha differentially regulate metastatic success. Cancer Cell. 2012; 21(1):52-65.

12. Liao D and Johnson RS. Hypoxia: a key regulator of angiogenesis in cancer. Cancer Metastasis Rev. 2007; 26(2):281-290.

13. Semenza GL. Cancer-stromal cell interactions mediated by hypoxia-inducible factors promote angiogenesis, lymphangiogenesis, and metastasis. Oncogene. 2012.

14. Mimeault $\mathrm{M}$ and Batra SK. Hypoxia-inducing factors as master regulators of stemness properties and altered metabolism of cancer- and metastasis-initiating cells. J Cell Mol Med. 2013; 17(1):30-54.

15. Mucaj V, Shay JE and Simon MC. Effects of hypoxia and HIFs on cancer metabolism. Int J Hematol. 2012; 95(5):464-470.

16. Wong CC, Zhang H, Gilkes DM, Chen J, Wei H, Chaturvedi P, Hubbi ME and Semenza GL. Inhibitors of hypoxia-inducible factor 1 block breast cancer metastatic niche formation and lung metastasis. J Mol Med (Berl). 2012; 90(7):803-815.

17. Zhong H, De Marzo AM, Laughner E, Lim M, Hilton DA, Zagzag D, Buechler P, Isaacs WB, Semenza GL and Simons JW. Overexpression of hypoxia-inducible factor 1alpha in common human cancers and their metastases. Cancer Res. 1999; 59(22):5830-5835.

18. Hanna SC, Krishnan B, Bailey ST, Moschos SJ, Kuan PF, Shimamura T, Osborne LD, Siegel MB, Duncan LM, O'Brien ET, 3rd, Superfine R, Miller CR, Simon MC, Wong KK and Kim WY. HIF1alpha and HIF2alpha independently activate SRC to promote melanoma metastases. J Clin Invest. 2013; 123(5):2078-2093.

19. Keith B, Johnson RS and Simon MC. HIF1alpha and
HIF2alpha: sibling rivalry in hypoxic tumor growth and progression. Nat Rev Cancer. 2012; 12(1):9-22.

20. Dales JP, Garcia S, Meunier-Carpentier S, Andrac-Meyer L, Haddad O, Lavaut MN, Allasia C, Bonnier P and Charpin C. Overexpression of hypoxia-inducible factor HIF-1alpha predicts early relapse in breast cancer: retrospective study in a series of 745 patients. Int J Cancer. 2005; 116(5):734-739.

21. Pollard JW. Tumor-educated macrophages promote tumor progression and metastasis. Nat Rev Cancer. 2004; 4(1):7178.

22. Qian BZ and Pollard JW. Macrophage diversity enhances tumor progression and metastasis. Cell. 2010; 141(1):39-51.

23. Kim JW, Evans C, Weidemann A, Takeda N, Lee YS, Stockmann C, Branco-Price C, Brandberg F, Leone G, Ostrowski MC and Johnson RS. Loss of fibroblast HIFlalpha accelerates tumorigenesis. Cancer Res. 2012; 72(13):3187-3195.

24. Franses JW, Baker AB, Chitalia VC and Edelman ER. Stromal endothelial cells directly influence cancer progression. Sci Transl Med. 2011; 3(66):66ra65.

25. Aird WC. Phenotypic heterogeneity of the endothelium: II. Representative vascular beds. Circ Res. 2007; 100(2):174190.

26. Martinive P, Defresne F, Quaghebeur E, Daneau G, Crokart N, Gregoire V, Gallez B, Dessy C and Feron O. Impact of cyclic hypoxia on HIF-1alpha regulation in endothelial cells--new insights for anti-tumor treatments. Febs J. 2009; 276(2):509-518.

27. Tang N, Wang L, Esko J, Giordano FJ, Huang Y, Gerber HP, Ferrara N and Johnson RS. Loss of HIF-1alpha in endothelial cells disrupts a hypoxia-driven VEGF autocrine loop necessary for tumorigenesis. Cancer Cell. 2004; 6(5):485-495.

28. Cattaneo MG, Cappellini E, Benfante R, Ragni $M$, Omodeo-Sale F, Nisoli E, Borgese N and Vicentini LM. Chronic deficiency of nitric oxide affects hypoxia inducible factor-1alpha (HIF-1alpha) stability and migration in human endothelial cells. PLoS One. 2011; 6(12):e29680.

29. Van der Wall H and Palmer A. On the AJR viewbox. Monomelic spread of metastatic disease due to proximal deep venous thrombosis. AJR Am J Roentgenol. 2006; 186(6):1797-1799.

30. Liu S, Guo W, Shi J, Li N, Yu X, Xue J, Fu X, Chu K, Lu C, Zhao J, Xie D, Wu M and Cheng S. MicroRNA135 a contributes to the development of portal vein tumor thrombus by promoting metastasis in hepatocellular carcinoma. J Hepatol. 2012; 56(2):389-396.

31. Ten VS and Pinsky DJ. Endothelial response to hypoxia: physiologic adaptation and pathologic dysfunction. Curr Opin Crit Care. 2002; 8(3):242-250.

32. Gao D, Nolan DJ, Mellick AS, Bambino K, McDonnell $\mathrm{K}$ and Mittal V. Endothelial progenitor cells control the angiogenic switch in mouse lung metastasis. Science. 2008; 319(5860):195-198. 
33. Holmgren L, O'Reilly MS and Folkman J. Dormancy of micrometastases: balanced proliferation and apoptosis in the presence of angiogenesis suppression. Nat Med. 1995; 1(2):149-153.

34. Joyce JA and Pollard JW. Microenvironmental regulation of metastasis. Nat Rev Cancer. 2009; 9(4):239-252.

35. Witz IP. Tumor-microenvironment interactions: the selectin-selectin ligand axis in tumor-endothelium cross talk. Cancer Treat Res. 2006; 130:125-140.

36. Powles T, Kayani I, Sharpe K, Lim L, Peters J, Stewart GD, Berney D, Sahdev A, Chowdhury S, Boleti E, Shamash J, Reynolds AR, Jones R, Blank C, Haanen J and Bex A. A prospective evaluation of VEGF-targeted treatment cessation in metastatic clear cell renal cancer. Ann Oncol. 2013.

37. Judy BF, Aliperti LA, Predina JD, Levine D, Kapoor V, Thorpe PE, Albelda SM and Singhal S. Vascular endothelial-targeted therapy combined with cytotoxic chemotherapy induces inflammatory intratumoral infiltrates and inhibits tumor relapses after surgery. Neoplasia. 2012; 14(4):352-359.

38. Skuli N, Majmundar AJ, Krock BL, Mesquita RC, Mathew LK, Quinn ZL, Runge A, Liu L, Kim MN, Liang J, Schenkel S, Yodh AG, Keith B and Simon MC. Endothelial HIF-2alpha regulates murine pathological angiogenesis and revascularization processes. J Clin Invest. 2012; 122(4):1427-1443.

39. Singh S and Gupta AK. Nitric oxide: role in tumor biology and iNOS/NO-based anticancer therapies. Cancer Chemother Pharmacol. 2011; 67(6):1211-1224.

40. Towner RA, Smith N, Doblas S, Garteiser P, Watanabe Y, He T, Saunders D, Herlea O, Silasi-Mansat R and Lupu F. In vivo detection of inducible nitric oxide synthase in rodent gliomas. Free Radic Biol Med. 2010; 48(5):691-703.

41. Shigyo H, Nonaka S, Katada A, Bandoh N, Ogino T, Katayama A, Takahara M, Hayashi $\mathrm{T}$ and Harabuchi $Y$. Inducible nitric oxide synthase expression in various laryngeal lesions in relation to carcinogenesis, angiogenesis, and patients' prognosis. Acta Otolaryngol. 2007; 127(9):970-979.

42. Olson $\mathrm{N}$ and van der Vliet $\mathrm{A}$. Interactions between nitric oxide and hypoxia-inducible factor signaling pathways in inflammatory disease. Nitric Oxide. 2011; 25(2):125-137.

43. Fukumura D, Kashiwagi $\mathrm{S}$ and Jain RK. The role of nitric oxide in tumor progression. Nat Rev Cancer. 2006; 6(7):521-534.

44. Mocellin S, Bronte V and Nitti D. Nitric oxide, a double edged sword in cancer biology: searching for therapeutic opportunities. Med Res Rev. 2007; 27(3):317-352.

45. Ho JJ, Man HS and Marsden PA. Nitric oxide signaling in hypoxia. J Mol Med (Berl). 2012; 90(3):217-231.

46. Melillo G, Musso T, Sica A, Taylor LS, Cox GW and Varesio L. A hypoxia-responsive element mediates a novel pathway of activation of the inducible nitric oxide synthase promoter. J Exp Med. 1995; 182(6):1683-1693.

47. Galkin A, Higgs A and Moncada S. Nitric oxide and hypoxia. Essays Biochem. 2007; 43:29-42.

48. Hagen T, Taylor CT, Lam F and Moncada S. Redistribution of intracellular oxygen in hypoxia by nitric oxide: effect on HIF1alpha. Science. 2003; 302(5652):1975-1978.

49. Bao F, Wu P, Xiao N, Qiu F and Zeng QP. Nitric oxidedriven hypoxia initiates synovial angiogenesis, hyperplasia and inflammatory lesions in mice. PLoS One. 2012; 7(3):e34494.

50. Hamed EA, Zakhary MM and Maximous DW. Apoptosis, angiogenesis, inflammation, and oxidative stress: basic interactions in patients with early and metastatic breast cancer. J Cancer Res Clin Oncol. 2012; 138(6):999-1009.

51. Guzik TJ, Korbut R and Adamek-Guzik T. Nitric oxide and superoxide in inflammation and immune regulation. $\mathrm{J}$ Physiol Pharmacol. 2003; 54(4):469-487.

52. Cacanyiova $\mathrm{S}$. The vasoactive role of nitric oxide: physiological and morphological aspects. Curr Pharm Biotechnol. 2011; 12(9):1294-1304.

53. Lu D and Kassab GS. Role of shear stress and stretch in vascular mechanobiology. J R Soc Interface. 2011; 8(63):1379-1385.

54. Burke AJ, Sullivan FJ, Giles FJ and Glynn SA. The yin and yang of nitric oxide in cancer progression. Carcinogenesis. 2013; 34(3):503-512.

55. Levine AB, Punihaole D and Levine TB. Characterization of the role of nitric oxide and its clinical applications. Cardiology. 2012; 122(1):55-68.

56. Murphy MP. Nitric oxide and cell death. Biochim Biophys Acta. 1999; 1411(2-3):401-414.

57. Frederiksen LJ, Sullivan R, Maxwell LR, MacdonaldGoodfellow SK, Adams MA, Bennett BM, Siemens DR and Graham $\mathrm{CH}$. Chemosensitization of cancer in vitro and in vivo by nitric oxide signaling. Clin Cancer Res. 2007; 13(7):2199-2206.

58. Matthews NE, Adams MA, Maxwell LR, Gofton TE and Graham $\mathrm{CH}$. Nitric oxide-mediated regulation of chemosensitivity in cancer cells. J Natl Cancer Inst. 2001; 93(24):1879-1885.

59. Barsoum IB, Hamilton TK, Li X, Cotechini T, Miles EA, Siemens DR and Graham CH. Hypoxia induces escape from innate immunity in cancer cells via increased expression of ADAM10: role of nitric oxide. Cancer Res. 2011; 71(24):7433-7441.

60. Crowell JA, Steele VE, Sigman CC and Fay JR. Is inducible nitric oxide synthase a target for chemoprevention? Mol Cancer Ther. 2003; 2(8):815-823.

61. Davie SA, Maglione JE, Manner CK, Young D, Cardiff RD, MacLeod CL and Ellies LG. Effects of FVB/NJ and $\mathrm{C} 57 \mathrm{Bl} / 6 \mathrm{~J}$ strain backgrounds on mammary tumor phenotype in inducible nitric oxide synthase deficient mice. Transgenic Res. 2007; 16(2):193-201.

62. Thomsen LL, Scott JM, Topley P, Knowles RG, Keerie 
AJ and Frend AJ. Selective inhibition of inducible nitric oxide synthase inhibits tumor growth in vivo: studies with 1400W, a novel inhibitor. Cancer Res. 1997; 57(15):33003304.

63. Molon B, Ugel S, Del Pozzo F, Soldani C, Zilio S, Avella D, De Palma A, Mauri P, Monegal A, Rescigno M, Savino B, Colombo P, Jonjic N, Pecanic S, Lazzarato L, Fruttero R, et al. Chemokine nitration prevents intratumoral infiltration of antigen-specific T cells. J Exp Med. 2011; 208(10):19491962.

64. Jayaraman P, Parikh F, Lopez-Rivera E, Hailemichael Y, Clark A, Ma G, Cannan D, Ramacher M, Kato M, Overwijk WW, Chen SH, Umansky VY and Sikora AG. Tumor-expressed inducible nitric oxide synthase controls induction of functional myeloid-derived suppressor cells through modulation of vascular endothelial growth factor release. J Immunol. 2012; 188(11):5365-5376.

65. Martinive P, Defresne F, Bouzin C, Saliez J, Lair F, Gregoire V, Michiels C, Dessy C and Feron O. Preconditioning of the tumor vasculature and tumor cells by intermittent hypoxia: implications for anticancer therapies. Cancer Res. 2006; 66(24):11736-11744.

66. Huang LE, Willmore WG, Gu J, Goldberg MA and Bunn HF. Inhibition of hypoxia-inducible factor 1 activation by carbon monoxide and nitric oxide. Implications for oxygen sensing and signaling. J Biol Chem. 1999; 274(13):90389044.

67. Chin K, Kurashima Y, Ogura T, Tajiri H, Yoshida S and Esumi H. Induction of vascular endothelial growth factor by nitric oxide in human glioblastoma and hepatocellular carcinoma cells. Oncogene. 1997; 15(4):437-442.

68. Williams JL, Cartland D, Hussain A and Egginton S. A differential role for nitric oxide in two forms of physiological angiogenesis in mouse. J Physiol. 2006; 570(Pt 3):445-454.

69. Abe H, Ishikawa W, Kushima T, Nishimura T, Mori C, Onuki A, Suzuki T, Ishii Y, Kansaku N, Miyazaki Y, Tanaka K, Morita H and Takizawa T. Nitric oxide induces vascular endothelial growth factor expression in the rat placenta in vivo and in vitro. Biosci Biotechnol Biochem. 2013; 77(5):971-976.

70. Kostourou V, Cartwright JE, Johnstone AP, Boult JK, Cullis ER, Whitley G and Robinson SP. The role of tumorderived iNOS in tumor progression and angiogenesis. Br J Cancer. 2011; 104(1):83-90.

71. Coupland LA, Chong BH and Parish CR. Platelets and P-selectin control tumor cell metastasis in an organ-specific manner and independently of NK cells. Cancer Res. 2012; 72(18):4662-4671.

72. Labelle M and Hynes RO. The initial hours of metastasis: the importance of cooperative host-tumor cell interactions during hematogenous dissemination. Cancer Discov. 2012; 2(12):1091-1099.

73. Sleeman JP. The metastatic niche and stromal progression.
Cancer Metastasis Rev. 2012; 31(3-4):429-440.

74. Fukumura D and Jain RK. Role of nitric oxide in angiogenesis and microcirculation in tumors. Cancer Metastasis Rev. 1998; 17(1):77-89.

75. de Vera ME, Shapiro RA, Nussler AK, Mudgett JS, Simmons RL, Morris SM, Jr., Billiar TR and Geller DA. Transcriptional regulation of human inducible nitric oxide synthase (NOS2) gene by cytokines: initial analysis of the human NOS2 promoter. Proc Natl Acad Sci U S A. 1996; 93(3):1054-1059.

76. Kubes P. Nitric oxide affects microvascular permeability in the intact and inflamed vasculature. Microcirculation. 1995; 2(3):235-244.

77. Aird WC. Phenotypic heterogeneity of the endothelium: I. Structure, function, and mechanisms. Circ Res. 2007; 100(2):158-173.

78. Lokhov PG and Balashova EE. Tumor-induced endothelial cell surface heterogeneity directly affects endothelial cell escape from a cell-mediated immune response in vitro. Hum Vaccin Immunother. 2013; 9(1):198-209.

79. Krause BJ, Prieto CP, Munoz-Urrutia E, San Martin S, Sobrevia L and Casanello P. Role of arginase-2 and eNOS in the differential vascular reactivity and hypoxia-induced endothelial response in umbilical arteries and veins. Placenta. 2012; 33(5):360-366.

80. Tsai YP and Wu KJ. Hypoxia-regulated target genes implicated in tumor metastasis. J Biomed Sci. 2012; 19:102.

81. Li Z, Wang D, Messing EM and Wu G. VHL proteininteracting deubiquitinating enzyme 2 deubiquitinates and stabilizes HIF-1alpha. EMBO Rep. 2005; 6(4):373-378.

82. Laughner E, Taghavi P, Chiles K, Mahon PC and Semenza GL. HER2 (neu) signaling increases the rate of hypoxiainducible factor 1alpha (HIF-1alpha) synthesis: novel mechanism for HIF-1-mediated vascular endothelial growth factor expression. Mol Cell Biol. 2001; 21(12):3995-4004.

83. Sceneay J, Parker BS, Smyth MJ and Moller A. Hypoxiadriven immunosuppression contributes to the pre-metastatic niche. Oncoimmunology. 2013; 2(1):e22355.

84. Hiratsuka S. Vasculogenensis, angiogenesis and special features of tumor blood vessels. Front Biosci. 2011; 16:1413-1427.

85. Shibue $\mathrm{T}$ and Weinberg RA. Metastatic colonization: settlement, adaptation and propagation of tumor cells in a foreign tissue environment. Semin Cancer Biol. 2011; 21(2):99-106.

86. Qian BZ, Li J, Zhang H, Kitamura T, Zhang J, Campion LR, Kaiser EA, Snyder LA and Pollard JW. CCL2 recruits inflammatory monocytes to facilitate breast-tumor metastasis. Nature. 2011; 475(7355):222-225.

87. Kafousi M, Vrekoussis T, Tsentelierou E, Pavlakis K, Navrozoglou I, Dousias V, Sanidas E, Tsiftsis D, Georgoulias V and Stathopoulos EN. Immunohistochemical study of the angiogenetic network of VEGF, HIF1alpha, VEGFR-2 and endothelial nitric oxide synthase (eNOS) in 
human breast cancer. Pathology oncology research : POR. 2012; 18(1):33-41.

88. Takala H, Saarnio J, Wiik H, Ohtonen P and Soini Y. HIF1alpha and VEGF are associated with disease progression in esophageal carcinoma. The Journal of surgical research. 2011; 167(1):41-48. 